\title{
Towards an unbiased view of science
}

\author{
Authors at Nature Communications now have the option to choose double-blind peer review
}

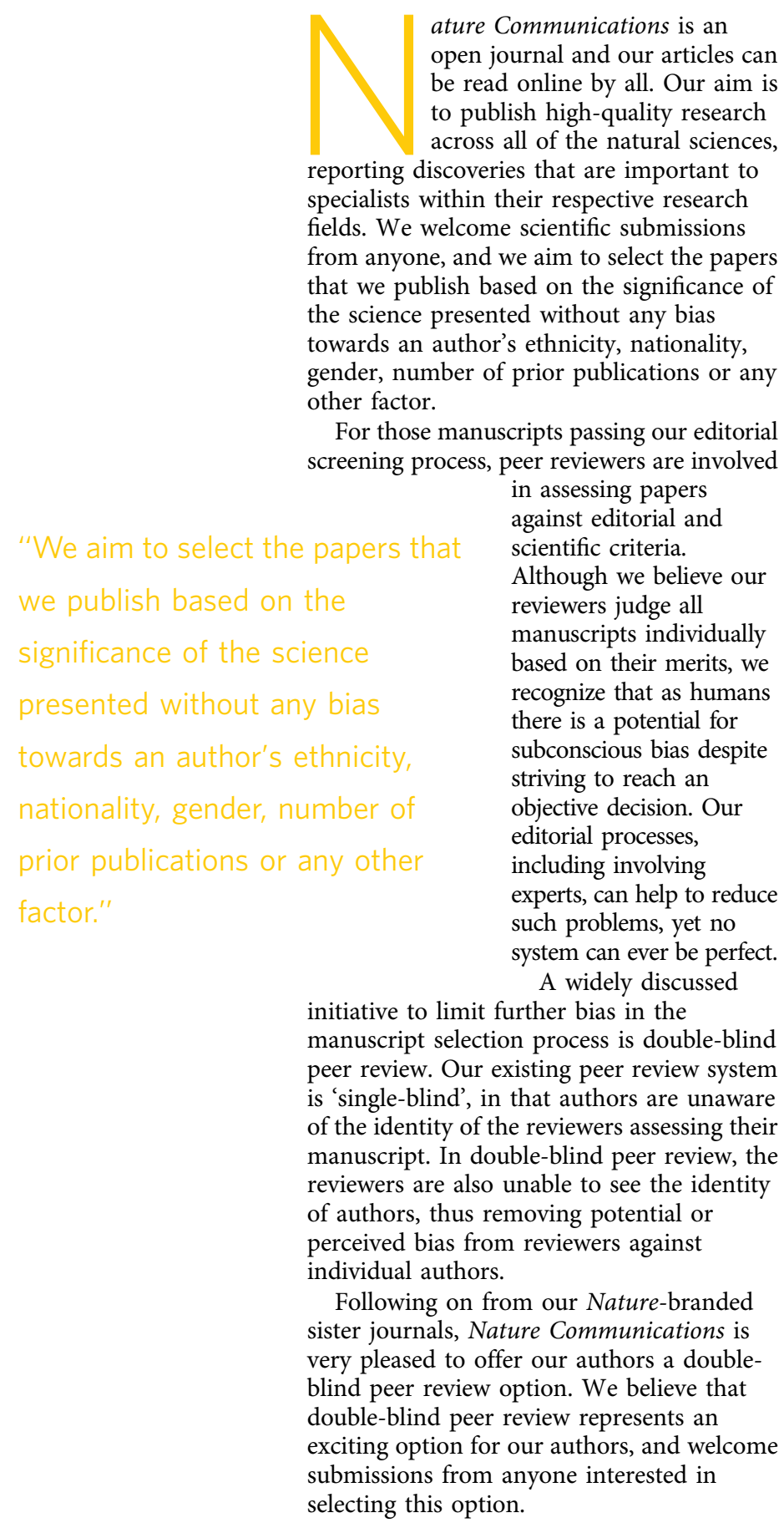

During double-blind peer review the identity of authors is known to the editors, and some might call for a 'triple-blind' system to eliminate the potential for editorial bias. This would not only be difficult to implement, it would also come at the cost of preventing direct discussions between editors and the authors they serve. However, most of our submissions are assessed by more than one editor, and decisions after double-blind peer review are, of course, made on the basis of the reports of reviewers who are not aware of the authors' identities. A checklist that might be useful to ensure that author identity is not readily apparent to reviewers can be found at http://www.nature.com/authors/doubleblind-checklist.pdf.

Double-blind peer review is not a complete solution to potential bias. For example, experts in a field serving as peer reviewers might be able to guess the identity of authors based on the science contained in the paper, or from what they know about the work from conference talks or posters. We already ask our reviewers to disclose any conflicts of interest when we approach them to review a paper, or if this becomes apparent during the review process. This requirement will remain for manuscripts submitted for double-blind peer review.

Double-blind peer review is only one measure to enhance the objectivity of the publication process. And it will not be the last. We will continue to assess further ways to improve our publication process and to provide the best possible service to our authors as well as to our readers. As with the other Nature-branded journals, we very much welcome your input on this initiative.

\section{Published online: 22 Jun 2015}

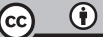

This work is licensed under a Creative Commons Attribution 4.0 International License. The images or other third party material in this article are included in the article's Creative Commons license, unless indicated otherwise in the credit line; if the material is not included under the Creative Commons license, users will need to obtain permission from the license holder to reproduce the material. To view a copy of this license, visit http://creativecommons.org/licenses/ by/4.0/ 